\title{
Toward Optimization of the Grain Boundary Character Distribution in Copper by Strain Annealing
}

\author{
W. E. King
}

A. J. Schwartz

This paper was prepared for submittal to the MRS Fall Meeting

Boston, MA

December 2-6, 1996

November 10, 1996

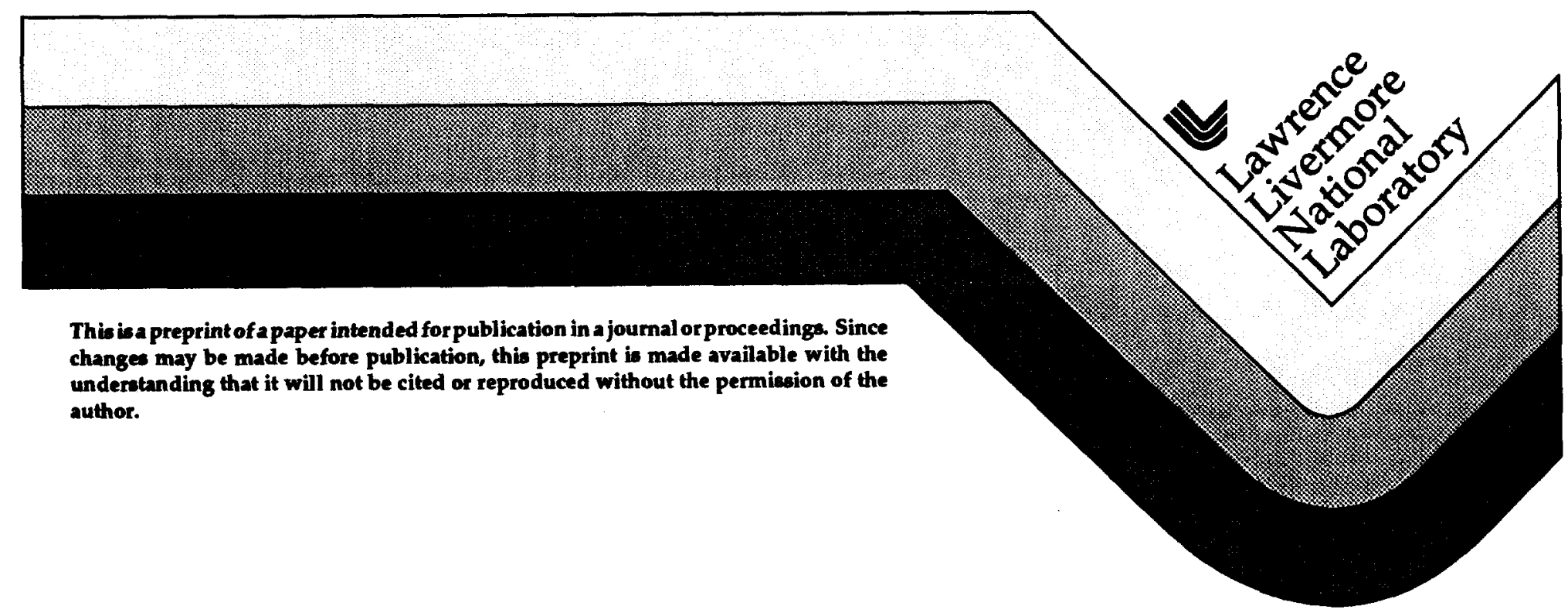




\section{DISCLAIMER}

This document was prepared as an account of work sponsored by an agency of the United States Government. Neither the United States Government nor the University of California nor any of their employees, makes any warranty, express or implied, or assumes any legal liability or responsibility for the accuracy, completeness, or usefulness of any information, apparatus, product, or process disclosed, or represents that its use would not infringe privately owned rights. Reference herein to any specific commercial products, process, or service by trade name, trademark, manufacturer, or otherwise, does not necessarily constitute or imply its endorsement, recommendation, or favoring by the United States Govemment or the University of California. The views and opinions of authors expressed herein do not necessarily state or reflect those of the United States Government or the Unjversity of California, and shall not be used for advertising or product endorsement purposes. 


\title{
TOWARD OPTIMIZATION OF THE GRAIN BOUNDARY CHARACTER DISTRIBUTION IN COPPER BY STRAIN ANNEALING
}

\author{
WAYNE E. KING AND ADAM J. SCHWARTZ
}

Chemistry and Materials Science Directorate, University of California, Lawrence Livermore National Laboratory, Livermore, CA 94550 USA

\begin{abstract}
We have used a two-step (low and high temperature) strain-annealing process to evolve the grain boundary character distribution (GBCD) in fully recrystallized oxygen-free electronic (OFE) $\mathrm{Cu}$ bar that was forged and rolled. Orientation imaging microscopy (OIM) [1-4] has been used to characterize the GBCD after each step in the processing. The fraction of special grain boundaries, "special fraction," was $\sim 70 \%$ in the starting recrystallized material. Three different processing conditions were employed: high, moderate, and low temperature. The high-temperature process resulted in a reduction in the fraction of special grain boundaries while both of the lower temperature processes resulted in an increase in special fraction up to $85 \%$. Further, the lower temperature processes resulted in average deviation angles from exact misorientation, for special boundaries, that were significantly smaller than observed from the high temperature process. Results indicate the importance of the low temperature part of the two-step strainannealing process in preparing the microstructure for the higher temperature anneal and commensurate increase in the special fraction.
\end{abstract}

\section{INTRODUCTION}

The failure of metals undergoing extreme deformation is thought to be ductile in nature, i.e., failure proceeds by the nucleation, growth, and linking of voids. An example of such an effect is shown in Figure 1 for the case of spall in $\mathrm{Cu}$ [5]. Some grain boundaries are observed to serve as potent sites for nucleation and growth of voids. Grain boundaries also play a key role in controlling the breakup time of explosively loaded shaped-charge jets as shown in [6]

Recently, a body of work has emerged which indicates that it may be possible to improve the performance of such systems by controlling the GBCD[7-14]. It has been shown that special boundaries have unique properties and materials with high fractions of special boundaries exhibit superior properties. For example, intergranular corrosion, grain-boundary segregation, creep, and intergranular fracture can all be significantly improved as the fraction of special grain boundaries

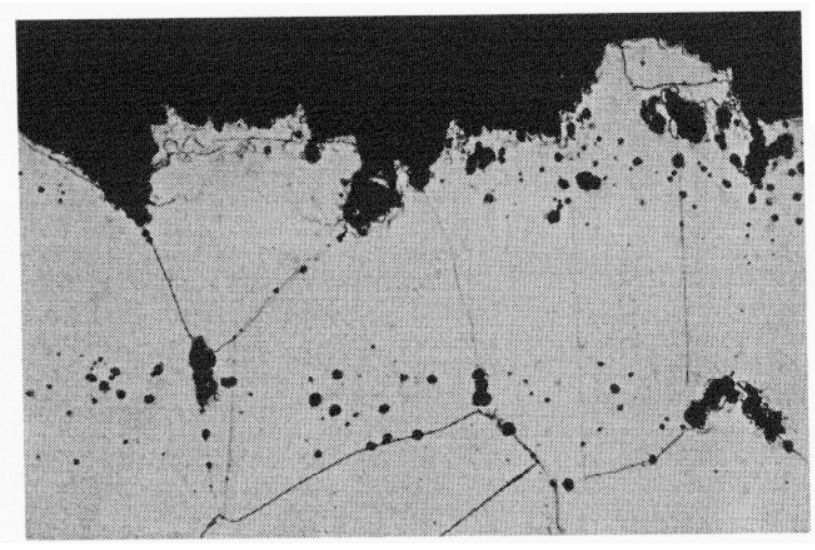

Figure 1. Optical micrograph showing the development of a spall plane in $\mathrm{Cu}$ (5) 
Figure 2. Radiographs of $\mathrm{Cu}$ shaped-charge jets. The jet at top is undoped OFE copper. The jet at the bottom was produced from $\mathrm{Cu}$ that had $\mathrm{S}$ segregated to the grain boundaries. The effect of the $S$ is earlier breakup of the jet and formation of asymmetric particles. (6)

increases[7-10, 12, 14]. Perhaps the most significant observation is that it is possible to exert control over the distribution of special and random grain boundaries through thermomechanical processing, which turns this from a scientific curiosity to a potential tool for enhancing material performance[11, 15-17].

Our approach is aimed at testing a hypothesis for the mechanism for GBCD optimization in $\mathrm{Cu}$, i.e., it is possible to optimize the GBCD in $\mathrm{Cu}$ by selectively removing random grain boundaries through a strain-annealing process. We begin with a fully recrystallized material, deform it by a crucial amount, then apply a specific heat treatment schedule. The deformation is not intended to be sufficient to induce full recrystallization upon heating, but is intended to localize the deformation energy at random boundaries (since random boundaries are expected to be less efficient at transmitting dislocations than special boundaries). Upon heating, the stored energy near these random boundaries is expected to provide sufficient driving force to rearrange these boundaries into special types.

\section{EXPERIMENTAL}

Fully recrystallized OFE $\mathrm{Cu}$ bar was forged and rolled to approximately $0.95 \mathrm{~cm}$ thickness. Sample coupons $\left(1 \times 1 \times 0.9 \mathrm{~cm}^{3}\right)$ were cut from the plate and prepared for observation by OIM using standard metallographic techniques. The GBCD of the starting material was measured using OIM. After this initial characterization, the specimens were deformed approximately $6 \%$ in compression and characterized using OIM. Finally, the $\mathrm{Cu}$ underwent a special two-stage heat treatment (shown in Table I), in an attempt to optimize the GBCD, followed by OIM characterization.

Table I. Strain-annealing treatments for the material studied in this investigation.

\begin{tabular}{lcccc}
\hline & \multicolumn{4}{c}{ Sample ID } \\
Process & OFE-1 & OFE-2 & OFE-3 & OFE-4 \\
Strain (\%) & -7 & -6 & -6 & -6 \\
\hline Heat & $8 \mathrm{H} / 334^{\circ} \mathrm{C}$ & $14 \mathrm{H} / 275^{\circ} \mathrm{C}$ & $14 \mathrm{H} / 225^{\circ} \mathrm{C}$ & $6 \mathrm{H} / 325^{\circ} \mathrm{C}$ \\
Treatment & $14 \mathrm{H} / 532^{\circ} \mathrm{C}$ & $7 \mathrm{H} / 375^{\circ} \mathrm{C}$ & $6 \mathrm{H} / 325^{\circ} \mathrm{C}$ & \\
\hline
\end{tabular}

The temperatures and times for the first strain-annealing treatment, OFE-1, were taken from the work of Thompson and Randle on $\mathrm{Ni}[15]$ scaled to the melting point of $\mathrm{Cu}$. The temperatures of OFE-2 were obtained by scaling the temperature of Thompson and Randle for Ni relative 
to the recrystallization point of $\mathrm{Ni}$ and applying the scaling to $\mathrm{Cu}$. The temperatures of $\mathrm{OFE}-3$ were selected to probe the effect of lower temperatures and minimize grain growth. OFE-4 was carried out to probe the importance of the two-step anneal.

\section{DATA ACQUISITION AND ANALYSIS}

Samples were observed in a Hitachi S2700 scanning electron microscope with an automated OIM attachment (TSL, Inc.) Typically, OIM scans were carried out in a hexagonal grid at $1.5 \mu \mathrm{m}$ resolution over areas $\sim 200 \times 200 \mu^{2}$. OIM data included the Cartesian coordinate location of each orientation corrected for the $70^{\circ}$ tilt of the sample, the Euler angles, a measure of the image quality of the backscatter diffraction pattern, and a measure of the confidence in indexing of the backscatter diffraction pattern (confidence index).

OIM data was analyzed using software developed at Lawrence Livermore National Laboratory in the IDL (Research Systems, Inc.) interactive data language. The first step in data analysis was to treat data points with low confidence index $(<0.1)$. Work at TSL, Inc. has shown, Figure 3, that the uncertainty in indexing of a backscatter diffraction pattern is nearly constant for confidence indices greater than 0.1 , whereas the uncertainty decreases precipitously for lower confidence indices[18]. An algorithm was developed to associate the orientation of a low confidence index point with that of the majority of its neighbors with common orientation. For example, it is likely that a low confidence index point will have several neighbors of common orientation. The misorientations of the six neighbors of the low confidence index point are assessed. The largest number of common-orientation, contiguous neighbors is determined. The orientation of the low confidence index point and its confidence index are assigned from the maximum confidence index point in the list of largest number of common-orientation contiguous neighbors.

The OIM data was then corrected for points with acceptable confidence index that were likely misindexed, for example, a single point in the center of a large grain whose orientation differs from its neighbors. First, each data point was surveyed to determine the number of neighbors with differing orientation from the data point (misorientation $>15^{\circ}$ ). If that number was five or six, the point was considered for correction of the orientation. The neighbors were then surveyed to determine the largest number of contiguous neighbors with common orientation. If that number was five or six, then the point in question was assigned the average orientation of those five or six neighbors.

With this corrected data set, plots were produced of confidence index as a function of position and overlaid with boundaries of angle $>15^{\circ}$. The Brandon criterion[19] was applied to identify those boundaries which were special in nature using tables produced by Adams et al.[20] The average angular deviation from exact misorientation was calculated for each special orienta-

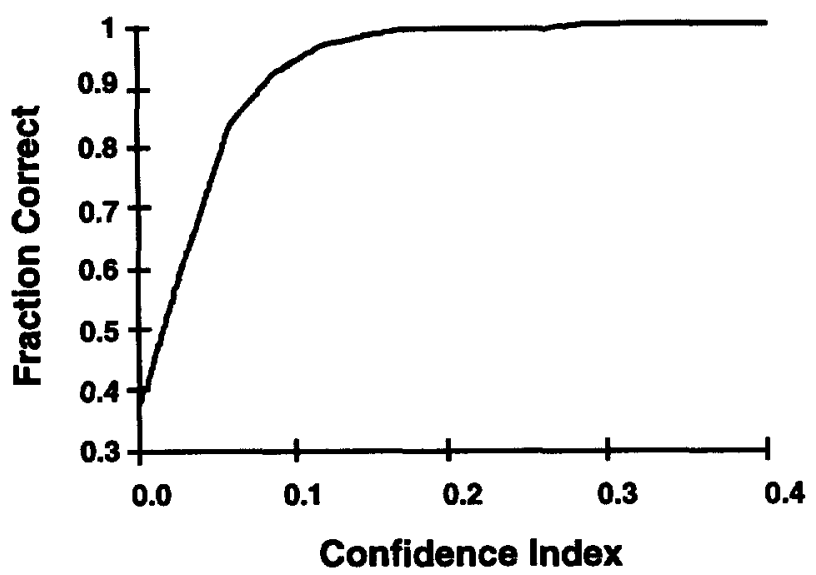

Figure 3. Fraction of diffraction patterns correctly indexed as a function of reported confidence index. (18) 
tion. Data was acquired from 2-5 areas for each heat treatment allowing for error bars corresponding to one-sigma uncertainty to be placed on the GBCD results.

\section{RESULTS}

On the average for this investigation, roughly $5-15 \%$ of the measured orientations are of low confidence index as illustrated in Figure 4a-d. Low confidence index points are often associated with grain boundaries since two patterns can overlap at these locations. Except for two cases $\left(-6 \%, 14 \mathrm{H} / 275^{\circ} \mathrm{C}\right.$ in (b) and $\left.6 \%, 14 \mathrm{H} / 225^{\circ} \mathrm{C}, 6 \mathrm{H} / 325^{\circ} \mathrm{C}(\mathrm{d})\right)$, the fraction of points with confidence index $\leq 0.1$ increases with deformation and decreases with annealing.

The typical recrystallized starting microstructure for the materials in Table I is shown in Figure 5. The initial grain size was $\sim 10 \mu \mathrm{m}$. The starting recrystallized material had a special fraction (total number of boundaries $3 \leq \Sigma \leq 29 /$ total number of boundaries) of nearly $70 \%$. Figure $6 a-d$ give the GBCD results for the four strain-annealing treatments. The effect of OFE-1 was a general decrease in the fraction of the special boundaries and a marked increase in $\Sigma 1$ type boundaries. This annealing treatment was accompanied by a significant and undesirable increase in grain size. Also, OFE-1 exhibited a larger statistical spread in fraction (Figure 6) and deviation angle (Figure 7) than OFE-2 and OFE-3 (solid white bars). Figure 7a shows that the 6\% compression resulted in a decrease in the average deviation from exact misorientation for $\sum 1$ and increases for the $\Sigma 3, \Sigma 9$, and $\sum 27$ boundaries compared with the recrystallized material. The annealing steps resulted in further decrease in the average deviation from exact misorientation for $\Sigma 1$ and an insignificant change for the $\Sigma 3, \Sigma 9$, and $\Sigma 27$. The special fraction decreased to $55 \%$ as a result of the OFE-1 treatments.

The OFE-2 and OFE-3 strain-annealing treatments exhibited significantly different behavior than OFE-1. In these cases, after the final anneal, the $\sum 1$ fraction dropped (Figure $6 \mathrm{~b}$ and $\mathrm{c}$ ) and the $\Sigma 3, \sum 9$, and $\sum 27$ fractions all increased. In contrast to OFE-1, the deviation from exact
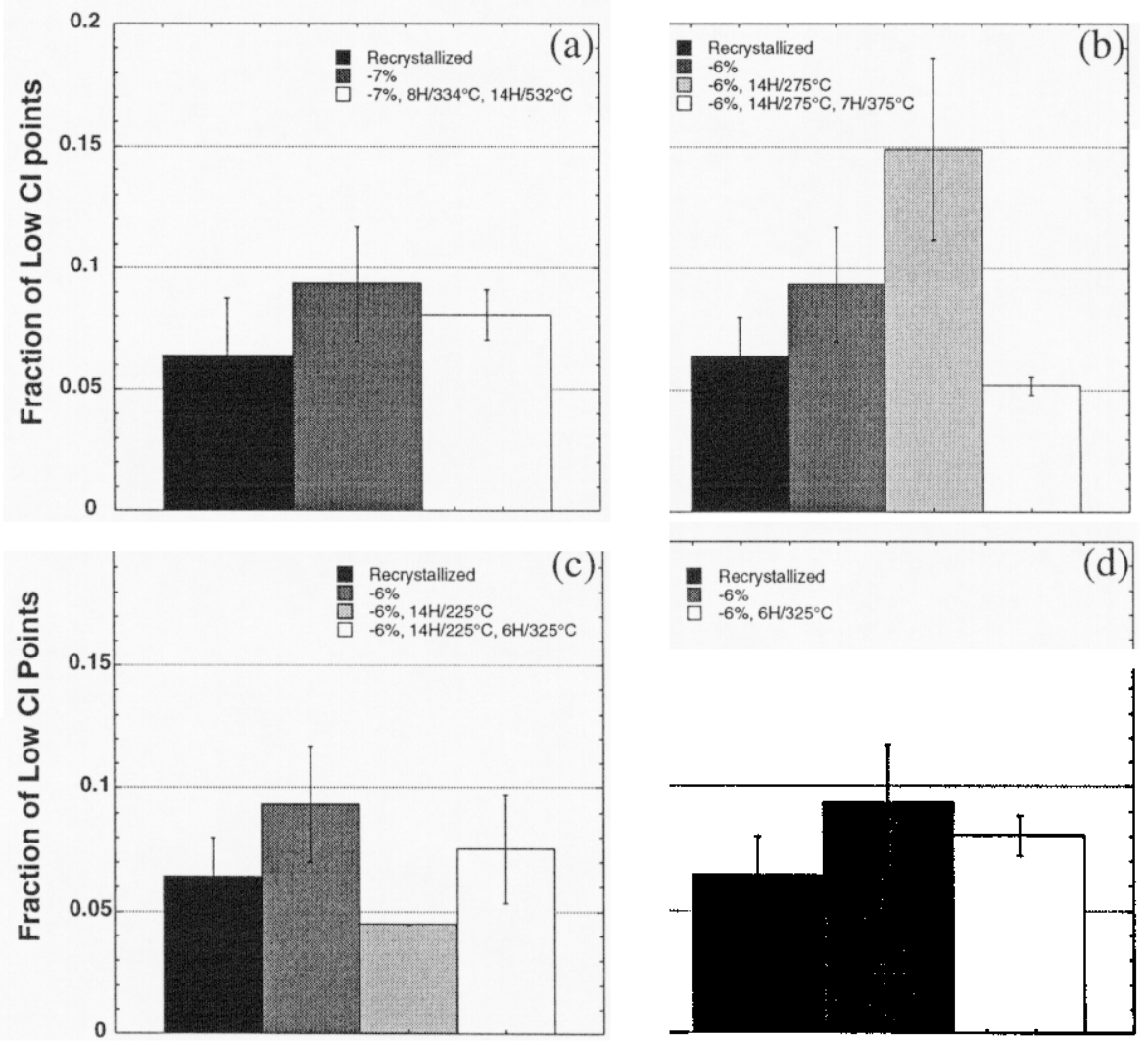

Figure 4. Fraction of data points of low confidence index as a function of strain annealing treatment: (a) OFE-1, (b) $O F E-2,(c) O F E-3$, and (d) OFE-4. 


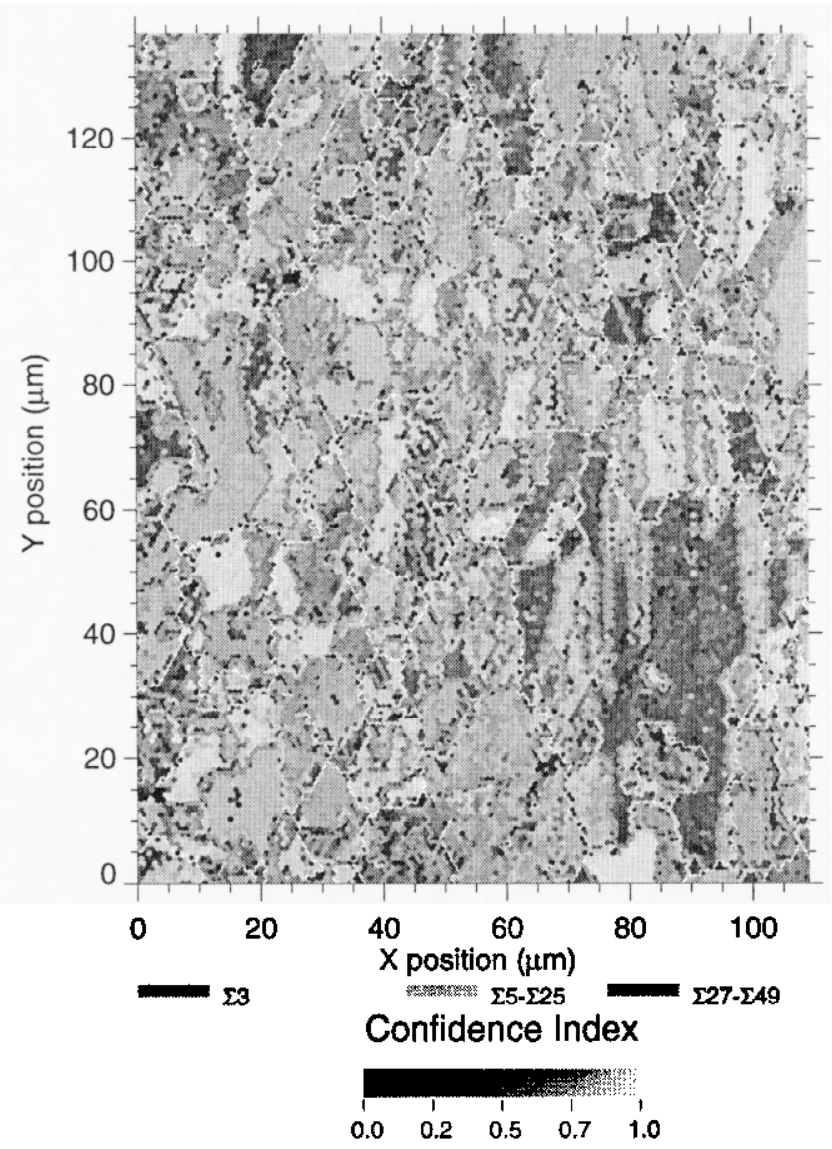

Figure 5. OIM image of the as recrystallized structure shaded by confidence index with special (grey shaded) and random (white) boundaries indicated.
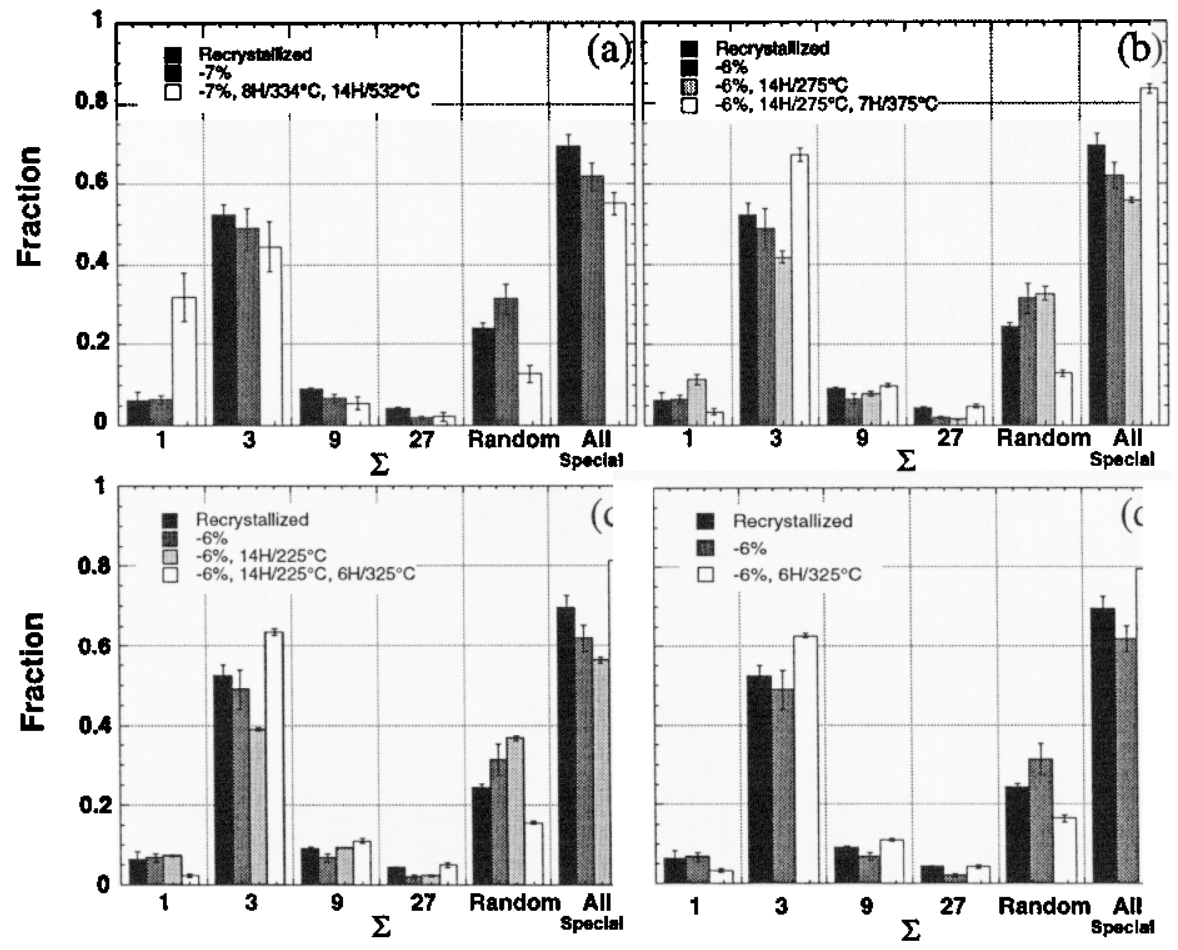

Figure 6. Fraction of boundaries of indicated type as a function of strain annealing treatment: (a) OFE-1, (b) OFE-2, (c) OFE-3, and (d) OFE-4. 

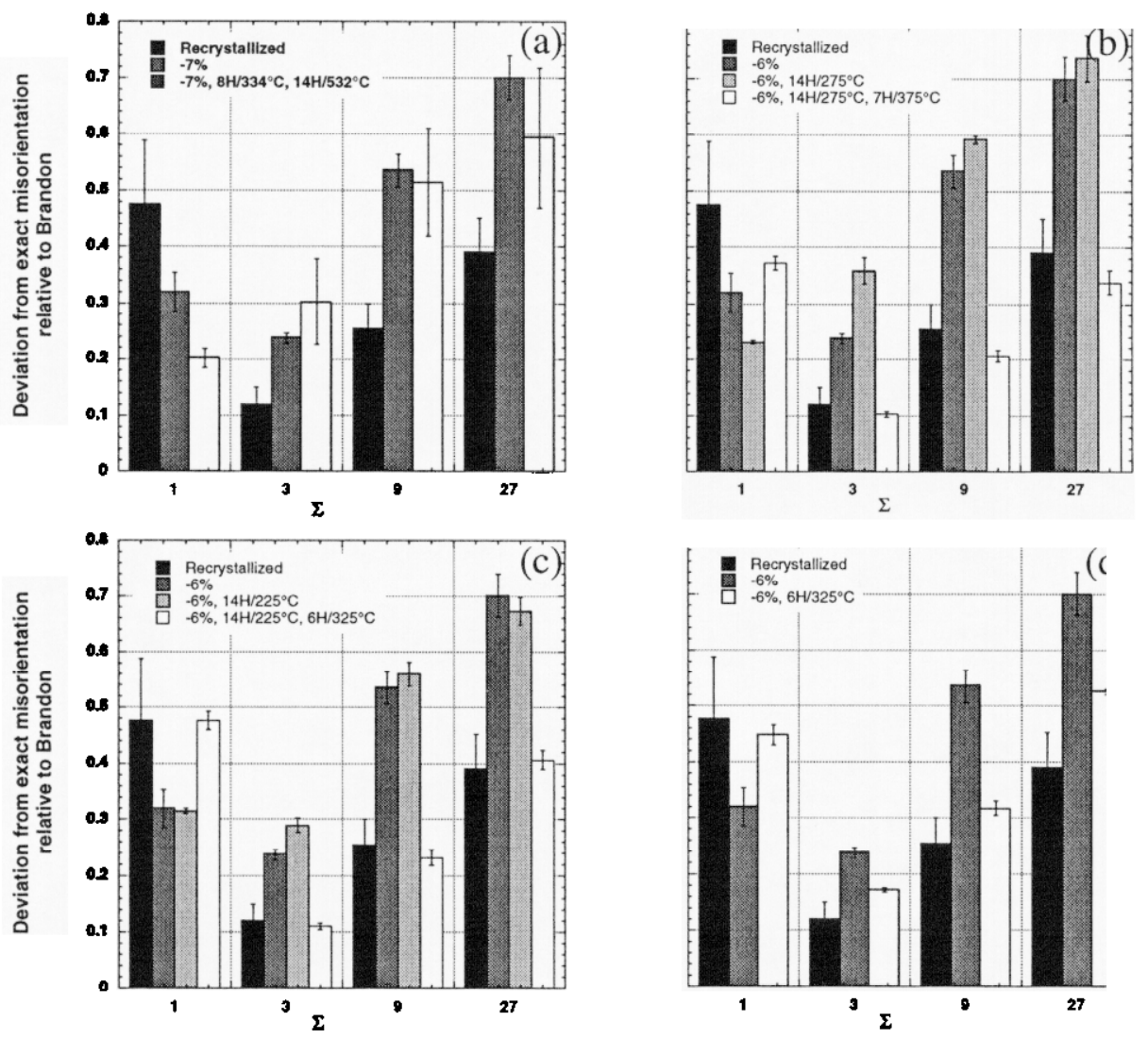

Figure 7. Deviation from exact misorientation plotted as a function of boundary type for each strain annealing treatment: (a) OFE-1, (b) OFE-2, (c) OFE-3, and (d) OFE-4.

misorientation is observed to decrease significantly as a consequence of the final anneal (Figure $7 \mathrm{~b}$ and $\mathrm{c}$ ). The special fractions for these latter experiments approached $85 \%$ compared with $55 \%$ in OFE-1.

The OFE-4 strain annealing treatment (no low temperature anneal) resulted in a significantly lower special fraction than both OFE-2 and OFE- 3 . The results of OFE-1, $-2,-3$, and -4 are summarized in Figure 8. The difference among OFE-2, -3 , and-4 is primarily in the $\Sigma 3$ fraction which is highest in OFE-3. Also, OFE-2 boundaries exhibited a smaller deviation from exact misorientation relative to the Brandon criterion than OFE-3 and OFE-4. One OIM scan from OFE-2, one from OFE-2, and one from OFE-3 were statistically outside of the error bars. This may indicate that the GBCD was not optimized for the entire sample volume and additional adjustments to strain, annealing time and temperature may be required.

\section{DISCUSSION AND CONCLUSIONS}

We have observed that the GBCD for forged, rolled, and recrystallized OFE copper can be significantly improved using a two-step strain-annealing process. Initially, a small compressive strain (6-7\%) is applied, we believe, to localize deformation at random grain boundaries in the recrystallized structure. Then a low temperature $\left(0.38-0.4 \mathrm{~T}_{\mathrm{m}}\right)$, long time $(14 \mathrm{H})$ anneal is performed. Although the exact function of this anneal is not currently known, it appears necessary to prepare the structure for the subsequent higher temperature anneal. In the higher temperature (0.44-0.48 $\left.\mathrm{T}_{\mathrm{m}}\right)$, long time $(6-7 \mathrm{H})$ anneal the special fraction increases significantly and there is an enhanced tendency for grains to have misorientation angles closer to exact misorientation. The lowest temperature heat treatment, OFE-3, caused an increase in $\Sigma 9$ and $\Sigma 27$ compared with OFE-2. 


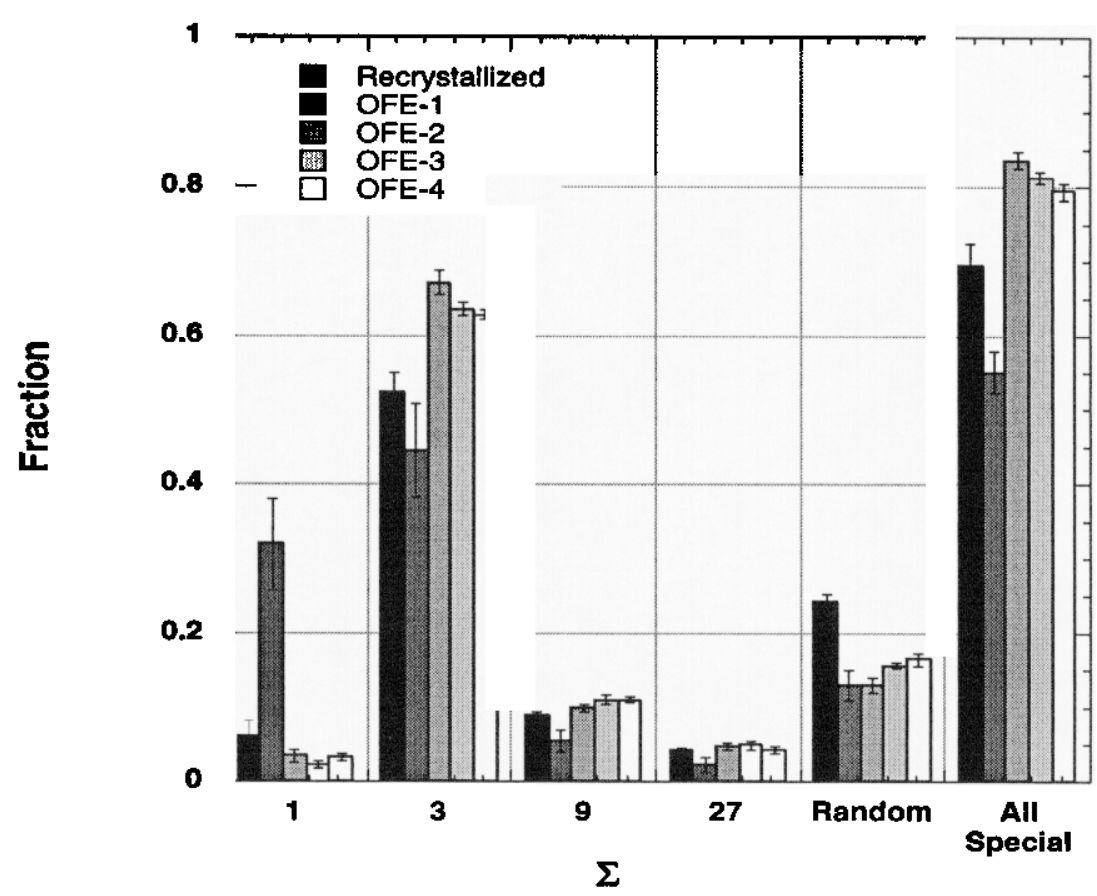

Figure 8. Fraction as a function of $\Sigma$ summarizing the recrystallized and the three heat treatments investigated in this study.

This work indicates the importance of the two-step strain-annealing process in the optimization of the GBCD. In OFE-1, the special fraction decreased because the temperatures used were too high. The increase in $\Sigma 1$ fraction appears to be an indicator of the failure to optimize GBCD. When the GBCD is optimized, the $\Sigma 1$ fraction is observed to decrease to a few percent.

In both OFE-2 and OFE- 3 the special fraction increased compared with the starting recrystallized material. The grain size also increased. Previous experiments have indicated the special fraction decreases as (grain size) ${ }^{-1 / 2.3}[14]$. The observation that special fraction can increase with grain size is similar to observations by Randle and Ralph[21]. Watanabe has reported that special fraction is proportional to $\Sigma^{-1 / 3}$ [14]. We have looked into this relation for eleven data sets and find that for this material, considering $\Sigma 3, \Sigma 9$, and $\Sigma 27$ only, that special fraction is proportional to $\Sigma^{-1.3 \pm 0.3}$. For the optimized structures, the exponents are closer to -1.5 .

\section{ACKNOWLEDGMENTS}

The author would like to express their appreciation to V. Randle, C. Thompson, D. P. Field, B. L. Adams, S. Wright, and D. Lassila for valuable technical discussions. The assistance of E. Sedillo and the metallography of R. Kershaw is gratefully acknowledged. This work is performed under the auspices of U.S. Department of Energy and Lawrence Livermore National Laboratory under contract No. W-7405-Eng-48.

\section{REFERENCES}

1. T. A. Mason and B. L. Adams, JOM-Journal of the Minerals Metals \& Materials Society, 46, p. 43-45 (1994)

2. B. L. Adams, Materials Science and Engineering A-Structural Materials Properties Microstructure and Processing, 166, p. 59-66 (1993) 
3. B. L. Adams, S. I. Wright and K. Kunze, Metallurgical Transactions A-Physical Metallurgy and Materials Science, 24, p. 819-831 (1993)

4. R. D. Doherty, I. Samajdar and K. Kunze, Scripta Metallurgica et Materialia, 27, p. 14591464 (1992)

5. D. H. Lassila, private communication.

6. D. H. Lassila, E. L. Baker, D. K. Chan, W. E. King and A. J. Schwartz, in 16th International Symposium on Ballistics, (in press,1996)

7. K. T. Aust, U. Erb and G. Palumbo, Materials Science and Engineering A-Structural Materials Properties Microstructure and Processing, 176, p. 329-334 (1994)

8. G. Avramoviccingara, K. T. Aust, D. D. Perovic, G. Palumbo and H. J. Mcqueen, Canadian Metallurgical Quarterly, 34, p. 265-273 (1995)

9. C. Cheung, U. Erb and G. Palumbo, Materials Science and Engineering A-Structural Materials Properties Microstructure and Processing, 185, p. 39-43 (1994)

10. L. C. Lim and T. Watanabe, Acta Metallurgica et Materialia, 38, p. 2507-2516 (1990)

11. G. Palumbo, P. J. King, K. T. Aust, U. Erb and P. C. Lichtenberger, Scripta Metallurgica et Materialia, 25, p. 1775-1780 (1991)

12. G. Palumbo and K. T. Aust, Canadian Metallurgical Quarterly, 34, p. 165-173 (1995)

13. T. Watanabe, Textures and Microstructures, 14, p. 739-744 (1991)

14. T. Watanabe, Scripta Metallurgica et Materialia, 27, p. 1497-1502 (1992)

15. C. B. Thompson and V. Randle, in 1996 MSA Annual Meeting, edited by G. W. Bailey, J. M. Corbett, R. V. W. Dimlich, J. R. Michael and N. J. Zaluzec (San Francisco Press, Inc. 1996), p. 356-357.

16. T. Watanabe, Materials Science and Engineering A-Structural Materials Properties Microstructure and Processing, 166, p. 11-28 (1993)

17. T. Watanabe, Textures and Microstructures, 20, p. 195-216 (1993)

18. Orientation Imaging Microscopy Software Version 2.0 User Manual, TSL, Inc., Provo, UT, 1996, pp. 3-5.

19. D. G. Brandon, Acta Metall, 14, p. 1479 (1966)

20. B. L. Adams, J. Zhao and H. Grimmer, Acta Crystallographica Section A-Foundations of Crystallography, 46, p. 620-622 (1990)

21. V. Randle and B. Ralph, Mat. Res. Soc. Symp. Proc., 122, p. 419-424 (1988) 


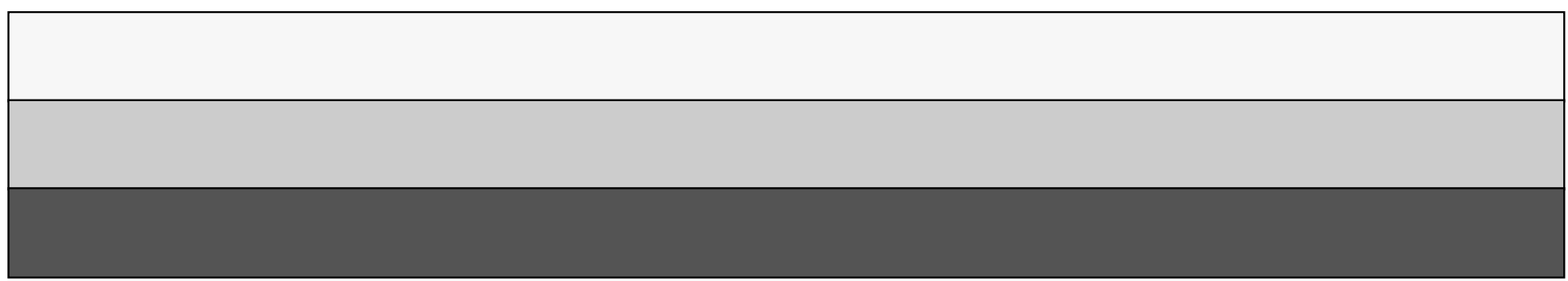

